\title{
Responding to a complex world: explorations in spatial planning
}

Article

Accepted Version

Chettiparamb, A. (2019) Responding to a complex world: explorations in spatial planning. Planning Theory, 18 (4). pp. 429-447. ISSN 1741-3052 doi: https://doi.org/10.1177/1473095218820554 Available at https://centaur.reading.ac.uk/80887/

It is advisable to refer to the publisher's version if you intend to cite from the work. See Guidance on citing.

To link to this article DOI: http://dx.doi.org/10.1177/1473095218820554

Publisher: Sage

All outputs in CentAUR are protected by Intellectual Property Rights law, including copyright law. Copyright and IPR is retained by the creators or other copyright holders. Terms and conditions for use of this material are defined in the End User Agreement.

\section{www.reading.ac.uk/centaur}

\section{CentAUR}

Central Archive at the University of Reading

Reading's research outputs online 


\title{
Responding to a Complex World: Explorations in Spatial Planning
}

\begin{abstract}
This article discusses three aspects in relation to complexity theory. First, from an understanding of time and space specificities in the rise of theories, it discusses the wider sociopolitical reasons that may account for the rise of Complexity Theory and its interest for planners today. The rise of the third sector in governance; the decentralisation of the nation state; the rise of informality; the exponential rise of information and knowledge in every sphere of human and non-human activity and the rise of new normative ideologies are argued to provide the social context for interest in Complexity Theory. Second, this article positions complexity theory within general social science theories and argues that complexity theory best suits the second order realm of social science theorisation. Third, this article positions complexity theory within planning theory and suggests that complexity theorists within planning might engage with the theory in three ways. These are by suggesting new ways of ordering of society and space by configuring or re-configuring planning systems in the first order; unravelling new opportunities for actors to work in society and space with largely selforganised entities and finally by searching for and discovering new dynamics for systems in the first order in society and space.
\end{abstract}

\section{Introduction}

In an earlier paper, I attempted to position complexity theory within the systems sciences and there I argued how complexity theory constitutes a third-generation of thought in studying systems (Chettiparamb, 2013). Here, I position complexity theory within a general tradition of social science theorisation. I search for explanations of why complexity theory is increasingly coming into its own in planning now and show how research in complexity theory today has taken several 'turns' that could well map on to traditions of social science research.

Complexity theory and its relevance have been largely advocated by authors within and without the planning discipline on the claim that society today is getting to be significantly more global, more complex (Urry, 2003), networked (Healey, 2007) and defined more so today by uncertainty (de Roo et al, 2012, Wezemael, 2010). Society has never been simple, local or nonrelational, but many would concur that the attributes have become ever more recognizable and pressing today. In 1973, Rittel and Webber argued for, what they characterized as the 'wicked' nature of planning problems (Rittel and Webber, 1973). The acceleration of uncertainty ever since has led to arguments for 'deep uncertainty' (Walker et al, 2013). Deep uncertainty is characterised by, for instance, the uncertainty of goals when actors cannot agree on the desirability, priority or consequences of particular courses of action and the uncertainty of means due to unclear system boundaries, system dynamics and unknown system inputs. The call now from within the planning discipline is therefore for more sophisticated theories and approaches within and of planning that can take these realities into account (de Roo, 2010; Innes and Booher, 2010).

Theories in general are products of time and space and they gain popularity and credence within a wider socio-political and cultural context. Successive waves of theories have followed broad changes in society and gain prominence not necessarily because they are 'new', but more because they resonate better with ideas and world views current in a changing society (Kuhn, 1996). Moreover, broad theoretical traditions seem to resonate across a great many disciplines, 
be it modernism, post- modernism, baroque, romantic, and so on, reinforcing the claim to the dialectic relationship between the emergence of ideas and changes in society.

Complexity theory is an umbrella term that encompasses distinct theoretical concepts and ideas (bifurcations, fractals, tipping points, autopoiesis and so on), which can trace their lineage back to one or other of the natural sciences. These concepts and ideas have in general emerged from observations of how systems behave over time when repeatedly subjected to feedback loops. As such they resonate with the genre of systems theories but are often referred to as "neosystems' theories (Knorr-Ketina, 1981, Roberts, 2002, Chettiparamb, 2018), a break away from the rather discredited past history of rigid systems thinking. Luhmann (2006) for instance, charts the evolution of systems thinking as starting from the theory of closed systems to the theory of open systems and now the current period of 'observing or self-referential systems' (p.37). A question of how theories that emerge from the natural sciences can be applied to the social sciences is an important one, but is not addressed in this paper. This is one for the future.

This article, explores four distinct but interconnected facets of the relationship between complexity theory and planning. First is the context for the emergence of the theory. Understanding this context helps a planning theorist to also understand the types of challenges that complexity theory responds to. Second, is the position of the theory in relation to structure and agency, two aspects of the social world that are regarded as fundamental to explain any change or stasis in the social sciences. Third, is the position of complexity theory within a hierarchy of theories that describe, interpret or normatively steer the social world. Appreciating the position of complexity theory with respect to structure and agency and other theories allow planning theorists to appreciate and position work within complexity theory in relation to other forms of explanation and other social science theories/concepts/models. Fourth, is to understand the ways in which planning scholarship has engaged with complexity theory. Mapping this allows planning theorists working with complexity theory to position their work in relation to one another, within the wide and often confusing landscape of complexity theory based explanations. In this article, I therefore answer each of the questions below:

1. What is the context for the emergence of complexity theory and in what ways might it resonate with characteristics, problems and issues in current society?

2. How can complexity theory be theoretically positioned within social sciences and its modes of explanations?

3. In what ways have complexity theory informed ongoing research within planning?

In the first section,the context for the emergence of complexity theory and its interest for planners are discussed. In the next section, forms of explanation in the social sciences in general are explored and an argument for Complexity Theory's ambit viz a viz structure and agency and other theories in the social sciences are put forward. Finally, complexity theory is related to planning theory and broad approaches adopted by scholars in planning are summarised. The paper ends with a conclusion that draws together key arguments.

\section{Complexity theory - Why now?}

This section goes beyond a claim of society as increasingly complex to explain the emergence of complexity theory. It attempts to identify the specific factors that might explain the "why now' question in order to guide planning theorists in understanding the kind of societal changes that complexity theory might help address. 
Theories have been understood as products of their time and space. The relationship of science to society is now generally acknowledged as being circular, with dense feedback loops from society influencing the kind of science carried out. Details of scientific practice which include choice of problems studied and methodologies used to substantiate a theory have been shown to be shaped by forces operating outside the laboratory - forces ranging from the mental makeup and experience of the scientist, to more institutionalised formal influences of funding, to chance and happenstance (Kuhn, 1996, pg 4). The general cultural receptivity to an idea has also been shown to play an important part in shaping the kind of science carried out, both in terms of the observations deemed acceptable for follow-up and also in terms of anticipation of support and recognition that society bestows upon the scientist (Toffler, 1984, pg xii, xii). The relationship is however reciprocal. Science also influences society (Toffler, 1984, pg xiv). It gives rise to metaphors, and shapes mental models that influence the socio-cultural realm, impacting on the manner in which we conceive of ourselves and the way we look upon the world (Outhwaite, 1994, pgs 20-37). The dialectic development gets entrenched first in academic and professional discourses and with time, it gets embedded more permanently in the formal, informal and symbolic interactions of society. This then has almost unconscious consequences on the ways in which we view the future, deem fit to deal with it and organize ourselves to carry on with our daily activities.

Way back in 1973, Horst Rittel and Melvin Webber argued that the nature of problems that planning had to deal with in their contemporary times could not be solved by the professional expertise available to planners then. The context for these problems that they highlighted in their seminal paper was:

The test for efficiency, that were once so useful as measures of accomplishment, are being challenged by a renewed preoccupation with consequences for equity. The seeming consensus, that might once have allowed distributional problems to be dealt with, is being eroded by the growing awareness of the nation's pluralism and of the differentiation of values that accompanies differentiation of publics. The professionalized cognitive and occupational styles that were refined in the first half of the century, based in Newtonian mechanistic physics, are not readily adapted to contemporary conceptions of interacting open systems and to contemporary concerns with equity. A growing sensitivity to the waves of repercussions that ripple through such systemic networks and to the value consequences of those repercussions has generated the recent re-examination of received values and the recent search for national goals (Rittel and Webber, 1973, p.156).

They argued that the above context led to problems of goal definition and problem definition and their consequences for equity, which they famously characterised as 'wicked' problems (Rittel and Webber, 1973, p.155). While Rittel and Webber defined the nature of the problem and its characteristics, it was more than a decade later that Karen Christensen actually mapped planning styles across degrees of certainty regarding means and ends, suggesting that very different planning styles are required for different combinations of means and ends uncertainty (Christensen, 1985). The above means-ends uncertainty has however now broadened to also appreciate concerns of uncertainty around adaptability to unknown circumstances, uncertainty over structural resilience/robustness of systems and uncertainty over feedback effects on systems over time. These in essence define what Walker et al (2013) term 'deep uncertainty'. So, if the above issues are capturing our attention now, more so than ever before, then why now?

Rather than a fully historic account, in this paper, I will focus on the last four decades during which time, in the main, Complexity Theory gained prominence within the social sciences. These are decades that have witnessed great social, economic and cultural changes, not just in the West, but also more globally. I discuss the main social changes that I argue have enabled the social sciences to embrace complex descriptions of the world and pay attention to concepts and ideas that perhaps better encapsulate the lived experiences of these decades. Each of these 
factors may not be a full explanation in themselves and their relative relevance will inevitably change with geographical contexts. They all nevertheless contribute to an explanation to a greater or lesser extent.

Western contexts have seen the gradual erosion of the welfare state and the top-down planning that accompanied it. The funding gap and the service gap that was left behind, was soon, wherever possible, taken up by bottom up and non-governmental, social enterprises, community organisations and self-help initiatives often referred to as the 'third sector' (Salamon, 1993, Borzaga and Defourny, 2003, Brandsen and Psetoff, 2006, Osborne, 2008, Billis, 2010). On the other hand, in non-Western contexts, the welfare state had never really been a strong entity and in the insterstices of the gaps left vacant by the state, localised initiatives formed and developed (Chettiparamb, 2006a). The proliferation of such initiatives then meant a landscape of distributed power, where horizontal power was as much a consideration as hierarchical power. This opened up question about how such entities form, sustain themselves and grow; how such self-organising initiatives are to be governed and to what extent; and more importantly for planning, how planning might be accomplished in a landscape of such varied non-state actors. There was little in planning theory hitherto to answer such new questions that were more noticeably arising.

The demise of the welfare state was also accompanied by the fragmentation of the nation state. The rise of sub-national governments, devolved governments, supra-national governments and parastatals were becoming visible both in the West and the non-West. This changehowever wasfelt acutelyin the hitherto strong national contexts within Europe. Multi-level governance and inter-governmental coordination, together with partnership working with the private sector were to become part of the planner's context in striving for and realising regional outcomes (Rhodes, 1994, MacLeod and Goodwin, 1999, Bache and Flinders, 2004, Mair, 2006, Jessop, 2008). How then might a planner plan within this mosaic of organisational plurality wherein responsibilities are fragmented? Again, there was little in conventional planning theory that could help planners in dealing with the new reality. Complexity theory grapples with this situation in two ways. First, it draws attention to mututal interactions and feedback dynamics of distributed architectures of agency (such as in agent-based modelling) so as to model/predict future outcome from the relations. Second, is to draw attention to processes and network architectures of structural relationships and feedbacks within empricially defined systems that are no longer closed or open, but are also now described as self-referential (see Luhmann, 2006, Chettiparamb, 2014).

The dispersed architecture of responsibility and the emergence of spontaneous self-organized initiatives was also of course accompanied by the 'information revolution' (Dertouzas and Dertouzas, 1998, Freeman and Louca, 2001). Data and information today is continuously produced, collected, analysed and consumed by governments, organizations, and individuals. The onset of the 'knowledge economy' (Boden and Miles, 2000, Dunning, 2002, Rodriguez, 2002, Powell and Snellman, 2004), with the burgeoning of knowledge in every conceivable sphere be it the environment, economy, technology, health or any other sphere, paradoxically left even more visible the limitations of knowledge. The inconvenient incursion of ignorance and chance injected a good measure of unpredictability and risk into even the most carefully planned processes. How then could the planning system deal with information on the vast number of issues it intersects with, in a society that also demands evidence-based decision making? Complexity theory draws attention to ways and means of designing and instituting systems that are no longer based on information processing capacities of a select few decision- 
makers/experts, but relies instead on feedback loops created through self-learning and selfcorrection in a system of multi-layered distributed responsibility.

The rise of informality in planning discourse is inevitable with the dispersion of responsibility, the undermining of top-down command structures, the demise of the welfare state and the rise of the third sector. The recognition of the 'informal' has led to closer scrutiny of the concept, not just as the excluded zone of the formal, but also as the medium within and through which much of social processes and outcomes are realized (De Soto 2000, Roy, 2005, Perry et al, 2007). The relationship of the formal and the informal is therefore increasingly called into question and with it the difficulty of planning for and in spite of informality. This then further contributes to the complexity that define current times. In its incorporation of distributed multilayered agencies with information processing and learning capabilities, in place of a top-down decision making structure, complexity theory soon attracted the attention of those working to understand the dynamics of the extra-formal as well.

Ideologies arise from the socio-cultural and political economic contexts of particular places and times. It is not surprising then that ideologies that match the complexity of times should arise. Normative positions advocating ideals such as active citizenship, social capital and participatory democracy have thus complemented the rising complexification of society giving initiatives based on such ideologies normative validity. Planning as a profession too embraced these normative positions as it struggled to make sense of the complexity of the times (Stivers, 1990, Chettiparamb, 2006a, Putnam, 2000, Pateman, 2000, Healey, 1992). Thus much of planning thought in the recent past has engaged with normative ideas of planning, especially in relation to questions of process. The 'how' of planning is justified by ideas of 'why' in planning, be it democracy, ideal speech situations, inclusiveness, active citizenship, equality, justice and so on as in ideas of advocacy planning, participatory planning, collaborative planning, and so on. Though challenged and critiqued on a number of levels, these positions continue to be relevant today. They do however leave an unexplored realm of 'deep uncertainty' as society goes though some of the changes and challenges described above.

As argued above, complexity theory focuses on difficult to describe, understand and predict multi-layered and distributed learning systems and attempts to understand how they work; what opportunities for individuals, organisations and society are possible, and from a governance/planning perspective, how attempts to govern and plan might be accomplished. It can therefore be argued that the interest in complexity theory and what it can tell us is by no means accidental. It is instead, very much an outcome of the socio-political pressures of the times that we live in.

In his 2010, book on planning and complexity, Gert de Roo suggests that "Planning Theory and complexity thinking are two different matters. It is therefore not easy to connect the two" (de Roo, 2010, p.19). This view rather problematically sees two different entities and sets forth an implicit aim to connect the two. However, planning thought has, in its evolution, resonated both with society as well as changing philosophical ideas in the social sciences, the arts and the humanities. Post modernism in art, architecture, the social sciences and planning too, followed from modernism in all these disciplines. With post-modernism came an increasing acknowledgment of diversity, history and 'the particular' opposed to the 'universal' placeless validity of the modernist agenda. Within planning, this gave impetus to the acknowledgement of different needs of different populations, and the differential impacts of hitherto 'neutral' planning initiatives on distinct population groups. It was the era of re-discovery of 'the particular' in multiple ways, including calls for the inclusion of often unheard voices in main 
stream discourse. This led to arguments for communicative/collaborative/participatory methods to be part of mainstream processes of planning for projects and spaces. Poststructuralism reflected the recognition of the disparate, subtle and sometimes positive workings of power through discourse, architecture, and everyday relations. Within planning, it gave rise to the unpacking of 'governmentality' and how governance is routinely achieved 'at a distance' and how power, now recognised as emanating from everywhere, structures everyday life. It was not long afterwards, that the recognition of the role and power of relations in enabling and constraining opportunities gave way to the analysis of networks in planning and the rediscovery of the explanatory power of networks. Relational mapping and network architectures soon led to the awareness of inanimate objects, their role in networks and recognition of processes of network working through the rise of actor network theory in the social sciences and planning. As argued earlier, complexity theory, through the rise of interest in concepts such as self-organisation, resilience, fractals, autopoiesis, second-order initiatives and so on characterize contemporary additions to an already existing rich mixture of analytical lenses current within both the social sciences and planning. The theory thus is not a separate entity struggling to connect with planning theory, but is more of a continuation of knowledge claims responding to changing times.

\section{Structure-Agency and Complexity Theory}

While the above section has argued for why complexity theory has captured the attention and curiosity of some planners and social scientists, for planning theorists, a cognitive schema to position the theory in relation to other dominant theories in the social sciences is needed. This section positions complexity theory viz-a-viz the structure-agency debate. This debate is chosen as modes of explanation in social sciences are fundamentally linked to either of the two.

\section{Structure and Agency in the Social Sciences}

Wellman (1997) suggests five forms of social inquiry within structural analysis. These can be summarised as analysis where 1) behaviour is interpreted as a result of structural constraints; 2) focus is on relationships between units; 3) the effects of patterned relationships of many members on one member of a structure is in focus; 4) there could be layers of structures and therefore layers of structural effects; and 5) there is a movement away from explanations that are reducible to individual actions. Structural modes of explanation are nevertheless criticised for its limitations too. For instance, Sayer (1992) points to an 'intellectualist fallacy' in the social sciences. Here the reporter or the scientist engaged in structural analysis, dealing with macro issues, when reporting on events or incidents tends to forget that for the actor or participant engaged in the activity, their goals are not clear, and the path taken is not a determined path but rather one prone to vulnerability or diversions. The ex post report produced compresses time, and strategies on the ground appear to be

"routine and mechanical execution of well-defined, perhaps reified, 'actions' undertaken according to firm 'rules' and 'roles"' (Sayer, 1992, pg 97).

Then practical and tacit knowledge which are often guided by a 'vague and unexamined practical consciousness' (Sayer, 1992, pg.15) is by and large underestimated in academic discourse of structural explanations. Sayer points out that when the ambiguity of practical knowledge is ignored and instead codified in propositional form, a mistrust between ordinary people and 'intellectuals' can arise. Resigned to this issue to a certain extent, he argues that structural analysis must still not be done away with as then that would only admit actor accounts. A realisation of the limits of structural analysis is advocated: 
"the above errors lie not in using structural analysis as a mode of abstraction but in using it as if it could provide concrete descriptions on its own; it provides a possible beginning to research but not an end" (original italics) (Sayer, 1992, pg 98).

The focus is thus on stressing the incompleteness of a structural account to fully describe concrete situations even when they remain valid. As Sanyal (2005) argues planning in the top remain a critical institutional mechanism for initiating social change, which planners cannot ignore. Therefore rather than moving wholesale into a critique of top-down planning, perhaps we should be focusing more on how to improve this through innovative planning that aims to create new and alternate institutional mechanisms.

Agency or action based theories stand in direct opposition to structural accounts as individual or organizational actor accounts are the objects of study. Giddens (1993) addresses the concern of whether a sociologist's accounts of social conduct can be seen as 'unnecessary and pretentious' given that participants already know of their life. Two justifications are advanced for what in addition a study of social life can contribute. First,

"no specific person can possess detailed knowledge of anything more than the particular sector of society in which he or she participates, so that there still remains the task of making into an explicit and composite body of knowledge that which is only known in a partial way by lay actors themselves" (Giddens, 1993, pg 137).

The above composite body of knowledge relates also to the idea of 'constructed universals' advanced by Alexander (1990). Second, Giddens argues:

"it is in any case not true that their [sociologists] endeavour can be no more than descriptive in character; their aim is to correct and improve upon notions used by actors themselves in interpreting their own actions and the actions of others" (Giddens, 1993, pg 137).

For Giddens, though sociological concepts must pick up differentiations of meanings which are relevant to the accomplishment of day to day interaction, they

"are in no way constrained to embody the same differentiations in their own formulation. ..."

(original italics) (Giddens, 1993, pg 160).

Theoretical accounts of agency then might construct 'universals' from the particularity of agential accounts and in doing so might suggest concepts and theories that can encapsulate the generality which is instantiated in that agency. These concepts and theories might then 1) describe a much larger picture than what any one person or actor can provide, 2) present insights that the actors may not themselves be aware of, and 3) introduce concepts or models that 'improve' upon frames of reference that actors themselves might otherwise use. Therefore theory based on agential accounts can be descriptive, cognitive in terms of providing or refining insights, as well as innovative, in terms of constructing new references for practice.

\section{Connecting Structure to Agency in the Social Sciences}

The above descriptions divide structure and agency and 'breaks up' social science explanation as there can be at least two different explanations for practice and social life. It is not therefore surprising that attempts to bridge the divide soon appeared (Knorr-Cetina and Cicourel, 1981). In this section, I review three attempts that seek to bridge this divide.. The first of these - the theory of structuration - is the most well-known among planning scholars mainly through the work of Patsy Healey. The second - the notion of habitus - may be less well-known, the third - the strategic-relational approach - has not yet attracted much attention, though references to this are now starting to appear.

Giddens' structuration theory, sees structure and agency as mutually dependent and coconstitutive. Here agents are reflective cognitive actors, constrained by structures that pre-exist. Agents however understand these structures and transform the rules around them which then 
changes such structures. The changed structures in turn impact again upon agents and the cycle continues through a process of structuration over time.

The concept of structuration involves that of the duality of structure, which relates to the fundamentally recursive character of social life, and expresses the mutual dependence of structure and agency (Giddens, 1979, pg 69)

Structuration theory thus advocates for the mutual constitution of both and the recursive impacts of one over the other, which then transform both over time. Structure is imagined here at one level and there is no explicit conceptual space that mediates between the recursive influences of one over the other.

The notion of 'habitus' by Bourdieu 'breaks up' the direct link between structure and agency. 'Habitus' for Bourdieu is constituted by history, they organize practice without consciousness or will of the actor, but is also a product of pre-existing objective conditions, which we might term as structures.

"The habitus - embodied history, internalized as a second nature and so forgotten as history

- is the active presence of the whole past of which it is the product. As such it is what gives

practices their relative autonomy with respect to external determinations of the immediate

present (Bourdieu, 1998, p.56)

It is in Bourdieu's work, though it precedes that of Giddens and was influential on Giddens, that we see a layered version of the social world. The habitus here though itself constituted by history, occupies a space between structure and agency. This introduces scale into the recursive relations. Bourdieu uses 'habitus' to account for the anthropological sense of belonging, customs and rules that are almost second-nature to practical life without necessarily invoking wider what he terms 'objective conditions'.

With the strategic-relational approach of Jessop (2001), we get a multiple layered vision of the interaction between structure and agency. Jessop argues that structure and agency relate to each other not just over time, but through scale too, with multiple realms of structure as well as multiple realms of possibilities for agency. Even if one might not agree with the prescription of processes occurring at each level in the model, I suspect that many would agree that it offers a more accurate account of structure-agency interactions in the social world.

\section{$\underline{\text { Structure - Agency and Complexity Theory }}$}

In this section, I relate complexity theory to the structure-agency debate and the idea of a multilayered scalar explanation. Scale is fundamental to complexity theory. The fundamental generative process in complexity theory, as mentioned earlier are the recursive feedback loops. The impact of each of these feedback loops can be observed in social phenomena be it in structures or agential action. I expand on this below.

In the three attempts discussed above to connect structure to agency, the observer or theorist is 'removed' from both structure and agency levels for she observes and can see the structure, the agent and also the interactions between the two. The position of the observer here is the realm of meta-theory which aims to theorise how structure and agency work together in the first level and what it then means for both. One can of course move on to further levels of observation to understand how the observer observes the first level. There is therefore the possibility for infinite regress in the layering constituted by infinite recursivity of observation.

Studies of the meta-realm are now familiar throughout the social sciences. We have, for instance, notions of meta-governance (Whitehead, 2003), meta-bureaucracy (Fenwick et al, 2012), meta-planning (Wilenski, 1981) and so on. We also have terms such as 'second order' deployed to describe layered dynamics in contexts including elections (Norris and Reif, 1997), 
policies (Cho et al, 2005), change (Hall, 2011), competencies (Daneels, 2008). A layered explanation for understanding planning and governance can also be seen in Savini, (2018), Moroni, (2018) and Chettiparamb (2007, 2018). This realm of second-order observation is the realm of complexity theory. Concepts such as fractals, bifurcations, phase-states, attractor states, autopoiesis and so on, essentially are statements of an observer who observes how systems as a whole (inclusive of structures and agents in the first level) behaves. The theory therefore provides the theorist with conceptual tools for describing these behaviours.

\section{Complexity Theory and the nature of social knowledge}

Having shown how complexity theory relates to fundamental modes of explanations in the social sciences, in this section, I position complexity theory with respect to the types of social knowledge that it produces and the relation it has to planning theories.

Diverse grounds for claiming scientific status for social knowledge are based upon conceptions of what count as goals for social science research. Zhao (2001, pgs 390-91) broadly classifies the goals of social science research into three - the nomological, the interpretive and the normative. For nomological theorists the goal of social sciences and thus social theory is to discover law-like statements that pertain to the social realm. Thus for Zetterberg

"the assumption here is that sociology will eventually discover a small number of propositions that are valid in several diverse contexts...This approach represents what we see as the main task of the sociological theorist - that is the discovery of general propositions" (1965, pgs 8,9, quoted in Zhao, 2001, pg 390).

Well within this goal is the mechanism-based approach in sociology, which aims to identify causal social mechanisms that will generate and explain observations and are thereby predictive in the sense that under like circumstances like outcomes can be expected. The interpretive approach opposing the nomological approach argues that the goal of social sciences is not to uncover any form of laws but is concerned with the interpretation of meaning and the understanding of 'lifeworlds' of actors. Thus for Taylor

"social theory is.....concerned with finding a more satisfactory fundamental description of what is happening. The basic question of all social theory is in a sense: what is really going on"? (1985, pg 91, quoted in Zhao, 2001, pg 390)

Sociological theories here are then narrative tales. The Normative approach sees social theory more as linked to practice and hence asks questions of what ought to be. Theories in this vein seek to articulate and advocate for specific positions that can guide social action. According to Steven Seidman for instance,

"social theory relates moral tales that have practical significance; they embody the will to shape history" (1991, pg 132, quoted in Zhao, 2001, pg 391).

The conceptual tools that Complexity Theory provides deals with the question of mechanisms of interaction in the observed system, addressing questions of 'how' systems behave rather than the normative directions that systems ought to follow (Chettiparamb, 2005). Authors in other disciplines have also noted this perceived 'limitation' of complexity theory. For instance Morrison, 2013 laments that complexity theory is silent on issues of values and ethics that are important for educational philosophy and Webb (2004) makes an attempt to provide Complexity Theory with a normative base in spite of the wider critique that prevails. Though within particular systems the implications of complexity theory might have normative value, this normative implication is not constant. For instance, while the analogy of the butterfly flapping its wings, associated with complexity theory, might be seen to embody normative value and hope in disciplines such as say health (Resnicow and Page, 2011), the theory in itself has been used to unravel mechanism of systems to explain for instance the spread of crime too 
(Beesley, 2009). Thus, while normative thinking is not entirely precluded in so far as complexity theory can be used in conjunction with normative positions, the theory itself provides answers to questions of 'how' focusing on the nomological.

\section{Complexity theory and Planning Theory}

Having positioned complexity theory viz a viz the general aims of social science knowledge production, in this section, I discuss planning theory in general and thereby argue for the place for complexity theory in planning theory.

Bunge (1973) creates an epistemological hierarchy for theories within social sciences. The topmost in this hierarchy is for Bunge mathematics and metaphysics. Both of these are abstract and thus devoid of content. They are thus qualified as meta-disciplinary. Third in the hierarchy is the level of the disciplinary sciences with theories of relevance to particular disciplines. These are less abstract but richer in substantive content. Systems theory is positioned as being less abstract than mathematics or metaphysics, but more abstract than the theories within disciplines (Boulding, 1956). Content wise they hover between the metaphysical realm and the disciplinary realm. Systems theories are therefore typically transdisciplinary in nature and cuts across multiple disciplines as does complexity theory. Bunge, in his "epistemological hierarchy" extends this further downwards to finally end in practices what he terms 'observables'. This hierarchy has been re-interpreted and modified by Zwick, (2001) who produce the following structure:

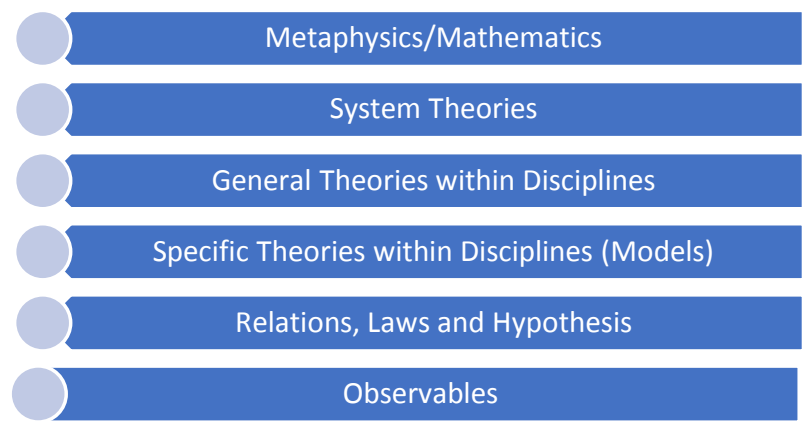

Source: Redrawn from Zwick (2001).

According to the above structure, theories can be built up inductively from lower level theories within disciplines by identifying isomorphisms between different theories or deduced deductively from higher level theories by adding substantive detail (Zwick, 2001). In an earlier publication, I have argued that abstraction is different from simplification. Abstraction makes a distinction between the general form of an entity and its specific manifestation. The general form continues to maintain validity in complexity of the specific context. Simplification however could result in the claim to the general form losing validity when the particularity of the situation is reintroduced (Chettiparamb, 2013).

Schatzi (2001), argues that the notion of a theory when talking about practice may be when 1) it offers a general and abstract account of practices or when 2) a general and abstract account is offered to practice. This conception of theory is contrasted against the more commonly known understanding of theory as linked to explanation or prediction. Thus

"systems of generalizations (or universal statements) that back explanations, predictions, and research strategies are theories. But so, too, for example, are typologies of social phenomena; models of social affairs; accounts of what social things (e.g, practices, institutions) are; conceptual 
frameworks developed expressly for depicting sociality; and descriptions of social life - so long as they are couched in general, abstract terms" (pg 4).

The everyday practical sphere is the foundation of theorisation. As Maffesoli (1996, pg 136) points out

"we find here the theoretical justification for the recent interest in the humdrum, the normal and the everyday; what is rejected often, like a subterranean centrality, provides a solid basis for the whole of sociology".

However, to be valid, lower level theories must be able to forge a link to higher level theories. Planning Theory is positioned between day to day practice (which seeks descriptive, cognitive and innovative aids that might help inform action, Forrester, 1993, 1999, Sandercock, 2000) and higher levels of theory from which it might derive conceptual/analytical categories. Planning theory can then by virtue of its position, contribute inductively to higher level more abstract explanations and predictions and also contribute deductively to practice and knowledge accumulation. This is a parallel elaboration of Friedmann's (1987) assertion of planning being a linkage between knowledge and action. The parallel assertion here is planning theory is a linkage between knowledge claims embedded in higher level theories of society per se and practice as realised in specific situations and contexts.

This level of theory is not occupied by planning alone. Functionally defined domains of social science such as economics, politics, or law have theories that occupy this domain. As long as the theories in these domains take off from a common conception of society, there is considerable overlap between the domains. What planning lays exclusive claim to is however the future, be it in terms of social reform, policy analysis, social learning or social mobilization (Friedmann, 1987), what Camhis (1979) terms as theories of planning as opposed to theories in planning. Theories in planning may come about through different streams with which planning engages, but theories of planning deal more with what can be termed as 'content less' entities such as 'objectives', 'goals', 'actions', 'decisions' etc which as Camhis argues, assume a substance of their own, and thereby become objects about which theories can be built (Camhis, 1979, pg 3).

Spatial planning is practised as a mode of governance with strong links to public administration in the ordering of space. It is also practised as a community driven non-governmental venture deeply embedded within local neighbourhoods. These two ways, as mentioned earlier, also reflect ways of intervening and governing in society i.e. first, by changing structural parameters through a top-down approach and second, by innovating and making a difference through bottom-up approaches using personal and organisational agency. Hetty van der Stoep argues that spatial planning has evolved from planning for society (top-down planning by an 'expert' often technocratic), to planning with society (planning with communities by acknowledging the need for shared knowledge often using collaborative/participatory methods) and now to planning by society (van der Stoep, 2013) where planners concede power and steer active participation and leadership by others in society. Complexity theory informs the latter space of planning by society. They are therefore theories both in and of planning (Camhis, 1973).

Planning thought influenced by complexity theory might engage with structural ideas in the second-order, for ordering space. In other words, it would ask questions about how might whole planning systems be designed to enable the self-evolving ordering of space in specified directions. It might also engage with agential interests and enquire into how understandings of system dynamics in the second-order might prompt actors to act in ways that enable selforganized initiatives to evolve in certain ways. Planning thought has also focused on discovering complex system dynamics in space with the help of computational models. The 
above three modes describe planning theorists engagement with complexity theory in order to improve planning practice.

Concepts and ideas associated with complexity theory may cut across all three modes. For instance, the computational side of planning, might discover and reveal fractal patterns in city growth or spatial forms and suggest how this comes to be (Batty, 2013). The environment within the model allow a stylised and sometimes simplified isolation and thus discovery of particular dynamics in complex systems that are difficult to recognise in the messy real world. It allows the discovery of the 'what', without always necessarily engaging with the 'why' or the 'so what'. The insights on 'what' dynamics however can potentially inform planning in triggering further enquiries. For instance, planning thought working with structural interventions might identify the 'why', the 'how' and the 'so what' after having recognised and identified such fractal forms in real life governance and space contexts (see for instance Chettiparamb 2013, 2005 for the how and why and Chettiparamb 2011 for the 'so what?' questions). Fractals might also inform agency by suggesting ways in which a planner might make a difference within existing institutional architectures. For instance, the new vocabulary can draw attention to macro and micro network and system dynamics enabling the planner to act as a network enabler or nurturer who strategically connects, stabilizes or enhances initiatives. The theory here cognitively widens the opportunity space. A similar argument can be made for other concepts too identified with complexity theory such as self-organisation, autopoiesis, fitness landscapes, attractors, bifurcations, phase spaces and so on. As mentioned earlier, the theory answers questions surrounding mechanisms and interventions informing planners on 'how to', rather than providing answers to normative arguments. In being potentially able to provide answers for 'how to' questions however, the theory takes us forward by making an invaluable contribution to the realisation of normative positions, a gap that is quite significant today in planning theory, yet much needed to advance planning practice.

To summarise I would argue that the questions for us who work in complexity theory and planning are three fold depending on one's theoretical inclination and skills. On the structural side, the questions might be:

- What new understandings and mechanisms for designing self-evolving planning and governance systems in order to steer society/space have complexity theory revealed?

- What research agendas do the above suggest?

Focusing on this aspect will allow the planner to exogeneously design appropriate institutions, laws, polcies and processes to ensue that self-evolving entities are nevertheless recursively steered through self-learning in a direction that they would not necessarily have adopted if left entirely to themselves. Expressed simply, it is the way that an institutional framework can be designed in which top-down processes and the bottom-up processes can meet and influence each other efficiently, effectively and continuously.

On the agential side of planning, the questions might be:

- What new understandings and actions for facilitating/dampening self-evolving planning and governance systems in order that these systems may plan for society/space have complexity theory enabled?

- What research agendas do the above suggest?

Focusing on this aspect, will allow the planner to position herself within a self-evolving system to consolidate planning outcomes by connecting parts horizontally, scaling in and out, and starting new feedback loops so as to influence self-learning processes and thus the evolution of institutional framings. Expressed simply it is the way in which a networked planner aware 
of her scale of operation will strategically influence self organised entities realise planning outcomes without necessarily being the decision-maker.

On the computational side of planning the questions might be:

- What rules of the game, within what kind of environment, explain outcomes of independently acting agents and how does this inform the ordering of space/society?

- What research agendas do the above suggest?

Focusing on this aspect will allow the planner to discover hitherto hard to discern system dynamics in the social world and independently study how such dynamics might have a place in the multi-facetted causal explanations of spatial practices and outcomes.

\section{Conclusions}

In this paper, I have attempted to do three things. In the first section, I have reflected on the social conditions that could have enabled the rise of interest in complexity theory. I argued that the rise of the third sector in governance; the decentralisation of the nation state; the rise of informality; the exponential rise of information and knowledge on every sphere of human and non-human activity and the rise of new normative ideologies provided the social context that demanded fresh answers to new problems and thus the space for the interest in complexity theory. My second attempt has been to understand forms of explanation in social science theory and relate this to complexity theory, thus positioning the same viz a viz social theory. Traditionally the social sciences have been concerned with explanations from either the structural side or the agential side. There have also been attempts to provide a schema for connecting structure and agency. Three examples of how this has been attempted was reviewed and I argued that all three attempt to provide a 'meta' view point which has been influential in a number of applied areas including planning. I argued that this meta-realm is the level for complexity theory. The theory in all its concepts attempt a description of how systems work in the first order. My third attempt has been to position complexity theory viz a viz planning theory. In order to do this the level of explanation of theories in general was reviewed. It was pointed out that middle level theories such as planning theories, might deductively draw upon concepts and ideas from higher level theories including systems theories that are also transdisciplinary, or it might draw upon subject theories that are more disciplinary. It was pointed out that planning theory might also contribute to new disciplinary knowledge by inductively drawing upon practices.

Finally, I argued that planning theory has always resonated with thought traditions in other disciplines and that complexity theory must therefore be understood within such a tradition. Thus complexity theory is no more separate from planning theory than any other previous traditions within planning theory. Complexity theorists within planning, working more structurally might work on understanding how complexity theory provides new understandings for steering systems in the first order. Those working more on the agency side might endeavour to understand how it provides new understandings for facilitating/dampening action in the first order systems. Complexity theorists in planning also work on discovering new concepts, rules and mechanisms that describe systems in the first order.

\section{References}

Alexander,J.C (1990) 'Beyond the Epistemological Dilemma: General Theory in a Postpositivist Mode’ In Sociological Forum, Vol 5, No 4, pgs 531-544. 
Bache,I and Flinders, M (2004) Multi-Level Governance and the Study of the British State. Public Policy and Administration, 19(1), 31 -51.

Batty,M (2013) The new Science of Cities. MIT Press: Massachusetts.

Beesley,J (2009) Organised Chaos: Seeing with new Eyes. Current Issues of Criminal Justice, $21, \mathrm{p} 343$.

Billis,D (2010) (ed) Hybrid Organizations and the Third Sector: Challenges for Practice, Theory and Policy. Palgrave Macmillan: New York.

Boden,M and Miles, (eds) (2000) Services and the Knowledge-based Economy, Continuum: London.

Borzaga,C and Defourny,J (2003) (eds) The Emergence of Social Enterprise. Routledge: London.

Boulding,K.E (1956) 'General Systems Theory - The Skeleton of Science'. In Management Science Vol 2, No 3. pgs 197-208

Brandsen,T and Pestoff,V (2006) Co-production, the third sector and the delivery of public services: An Introduction. Public Management Review, 8(4), 493-501.

Bunge,M (1973) Method, Model and Matter Reidel : Boston

Camhis,M (1979) Planning Theory and Philosophy Tavistock Publications: London

Chettiparamb,A. (2005) Fractal spaces in planning and governance, Town Planning Review, 76(3) 317-340.

Chettiparamb,A. (2006a) 'Bottom-up Planning and the Future of Planning Education in India. Journal of Planning Education and Research, 26 (2), 185-194.

Chettiparamb,A (2006b) Metaphors in Complexity Theory and Planning. Planning Theory, 5(1), 71-91.

Chettiparamb,A. (2007) 'Steering Across Scales: Applying Strategic-Relational Approach To A Study Of Land Mobilisation For Road Widening In Kochi', Journal of International Development 19(3), 413-427.

Chettiparamb,A, Chakkalakal,M and Chedambath,R (2011) In my backyard! An alternative model of solid waste management. International Planning Studies, 16(4), 313-331.

Chettiparamb,A (2013) Fractal Spatialities. Environment and Planning D: Society and Space, 31(4) 680-692.

Chettiparamb,A. (2014) Complexity Theory and Planning: Examining 'fractals' for organising policy domains in planning practice. Planning Theory, 13(1) 5-25. 
Chettiparamb, A. (2018) Meta-operations, autopoiesis and neo-systems thinking: What significance for spatial planners? Planning Theory 17(4), 628-643.

Cho, C.L., Kelleher, C.A., Wright, D.S. and Yackee, S.W., 2005. Translating national policy objectives into local achievements across planes of governance and among multiple actors: Second-order devolution and welfare reform implementation. Journal of Public Administration Research and Theory, 15(1), pp.31-54.

Christensen,K.S. (1985) 'Coping with uncertainty in Planning'. Journal of the American Planning Association, 15(1), 63-73.

Danneels, E., 2008. Organizational antecedents of second-order competences. Strategic Management Journal, 29(5), pp.519-543.

De Roo,G (2010) 'Being or becoming? That is the Question! Confronting Complexity with Contemporary Planning Theory'. In de Roo and Silva (eds) A Planner's Encounter with Complexity. Ashgate. Farnham. Pgs 19-40.

De Roo,G, Hiilier,J and Wezemael, JV (2012) Complexity and Planning. Ashgate: Farnham.

De Soto, H., (2000). The mystery of capital: Why capitalism triumphs in the West and fails everywhere else. Basic Civitas Books: New York.

Dertouzos, M.L and Dertouzos,M.L (1998) What Will be: How the New World of Information Will Change Lives. Harper-Collins Publishers: New York.

Dunning,J.H (2000) Regions, Globalization and the Knowledge-based economy, Oxford University Press: Oxford.

Fenwick, J., Miller, K.J. and McTavish, D, (2012). Co-governance or meta-bureaucracy? Perspectives of local governance'partnership'in England and Scotland. Policy \& Politics, 40(3), pp.405-422.

Freeman,C and Louca,F (2001) As Time Goes By: From the Industrial Revolutions to the Information Revolution. Oxford University Press: Oxford.

Friedman,J (1987) Planning in the Public Domain - From Knowledge to Action Princeton University Press: Princeton.

Forester,J (1993) 'Learning From Practice Stories: The Priority of Practical Judgement' In Fischer,F and Forrester,J (eds) The Argumentative Turn in Policy Analysis and Planning, UCL Press: London

Forrester, J (1999) The Deliberative Practitioner: Encouraging Participatory Planning Processes The MIT Press: London.

Giddens,A (1993) New Rules of Sociological Method-A Positive Critique of Interpretive Sociologies (Second edition) Polity Press: Cambridge. 
Giddens, A (1979) Central problems in Social Theory: Action, Structure and Contradiction in Social Analysis. University of California Press: California.

Hall, C.M,(2011) Policy learning and policy failure in sustainable tourism governance: From first-and second-order to third-order change?. Journal of Sustainable Tourism, 19(4-5), pp.649-671.

Healey,P (1992) Planning through Debate: The Communicative Turn in Planning Theory. Town Planning Review, 63(2), 143-162.

Healey,P (2007) Urban Complexity and Spatial Strategies: Towards a relationsl Planning for our Times. Routledge: London.

Innes, J.E and Booher, D.E (2010) Planning with Complexity: An Introduction to Collaborative Rationality for Public Policy. Routledge: London.

Jessop,B (2008) The Rise of Governance and the Risks of Failure: The Case of Economic Development. International Social Science Journal, 50(155), 29-45.

Jessop B (2001) Institutional (re)turns and the strategic-relational approach. Environment and Planning A, 33 (7): 1213-1235.

Knorr-Cetina,K and Cicourel,A.V (1981) (eds) Advances in Social Theory and Methodology - Toward an Integration of Micro- and Macro- Sociologies. Routledge \& Kegan Paul: London.

Kuhn,T.S (1996) The Structure of Scientific Revolutions. (Third edition). University of Chicago Press: London.

Luhmann.N (2006) System as Difference. Organization. 13(1), 37-57.

MacLeod,G and Goodwin,M (1999) Space Scale and State Strategy: Rethinking Urban and Regional Governance. Progress in Human Geography, 23(4), 503-527.

Maffesoli,M (1996) Ordinary Knowledge - An Introduction to Interpretive Sociology (Translated by Macey,D) Polity Press: Cambridge

Mair,P (2006) Ruling the Void: The Hollowing of Western Democracy. New Left Review, 42, $25-51$

Moroni,S (2018) Constitutional and post-constitutional problems: Reconsidering the issues of Public Interest, Agonistic Pluralism and Private Property in Planning. Planning Theory, Online First: https://doi.org/10.1177/1473095218760092

Morrison, K(2008) Educational Philosophy and the Challenge of Complexity Theory, Educational Philosophy and Theory, 40:1, 19-34.

Norris, P. and Reif, K., 1997. Second-order elections. European Journal of Political Research, 31(1), pp.109-124. 
Osborne,S.P (2008) (ed) The Third Sector in Europe: Prospects and Challenges. Routledge: New York.

Outhwaite,W (1994) Habermas- A Critical Introduction. Polity Press: Cambridge

Pateman,C (2012) Participatory Democracy Revisited. Perspectives on Politics, 10(1), 7-19.

Perry,G.E, Maloney,W.F, Arias, O.S. Faznzylber,P, Mason, A.D, Saavedra-Chanduvi,J (2007) Informality: Exit and Exclusion. The World Bank. Washington DC.

Portugali,J (2006) Complexity theory as a link between space and place, Environment and Planning A, 38(4), 647-664.

Powell,W.W and Snellman,K (2004) The Knowledge Economy. Annual Review of Sociology, 30, 199-220.

Putnam,R.D (2000) Bowling Alone: America's Declining Social Capital. In Crothers L., Lockhart C. (eds) Culture and Politics. Palgrave Macmillan, New York

Resnicow,K and Page, S,E (2011) Embracing Chaos and Complexity: A Quantum Change for Public Health. American Journal of Public health, 98(8), 1382-1389.

Rhodes,R.A.W (1994) The Hollowing out of the State: The Changing Nature of the Public service in Britain. The Political Quarterly, 65(2), 138 - 151.

Rittel, H.W.J. and Webber, M.M (1973) Dilemmas in a General Theory of Planning. Policy Sciences, 4(2), 155-169.

Roberts,S (2002) Against a Systemic Legal History. Rechtsgeschichte-Legal History. 21-25.

Rodriguez, M.J (2002) The New Knowledge Economy in Europe: A Strategy for International Competitiveness and Social Cohesion. Edward Elgar Publishing: Cheltenham.

Roy,A (2007) Urban Informality: Toward an Epistemology of Planning. Journal of the American Planning Association. 71 (2), 147-158.

Salamon,L.M (1994) The Rise of the Non-Profit Sector. Foreign Affairs. 73(4) 109-122.

Sandercock,L (2000) Towards Cosmopolis. John Wiley \& Sons: New York

Sanyal,B (2005) Planning as Anticipation of Resistance. Planning Theory, 4(3), 225-245.

Savini, F (2018) Responsibility, Polity, Value: The (un)changing norms of Planning Practices. Planning Theory. Online First: https://doi.org/10.1177/1473095218770474

Sayer,A (1992) Method in Social Science - A Realist Approach Routledge: London.

Savigny,E (eds) The Practice Turn in Contemporary Theory Routledge: London

Schatzi,T,R (2001) 'Introduction; Practice Theory’ In Schatzi,T,R, Knorr Cetina,K and Von 
Seidman,S (1991) The End of Sociological Theory: The Postmodern Hope. Sociological Theory, 9, p. 131-146.

Stivers, C (1990) The Public Agency as Polis: Active Citizenship in the Administrative State. Administration \& Society. 22(1), 86-105.

Taylor,C (1985) Philosophy and the Human Sciences: Philosophical Papers 2. Cambridge University Press: New York

Toffler,A (1984) 'Science and Change'. In Prigogine,I and Stengers,I Order out of ChaosMan's New Diologue with Nature. Fontana Paperbacks : London.

Urry,J (2003) Global Complexities. Polity Press: Cambridge.

Walker,W.E, Haasnoot,M and Kwakkel,J.H (2013) Adapt or Perish: A Review of Planning Approaches for Adaptation Under Deep Uncertainty. Sustainability, 5(3) 955-979.

Webb,J (2004) Law, Ethics and Complexity: Complexity Theory \& The Normative Reconstruction of law. Cleveland State Law Review, 53, p.227.

Wellman, B (1997) Structural analysis: From method and metaphor to theory and substance. Contemporary Studies in Sociology, 15, 19-61.

Wezemael,J.V (2010) Urban Governance and Social Complexity. In In de Roo and Silva (eds) A Planner's Encounter with Complexity. Ashgate. Farnham. Pgs 283-307.

Wilensky, R., 1981. Meta-planning: Representing and using knowledge about planning in problem solving and natural language understanding. Cognitive science, 5(3), pp.197-233.

Whitehead, M., 2003. 'In the shadow of hierarchy': meta-governance, policy reform and urban regeneration in the West Midlands. Area, 35(1), pp.6-14.

Zetterberg,H.L (1965) On Theory and Verification in Sociology The Bedminster Press:

Totowa

Zhao,S (2001) 'Metatheorising in Sociology' In Ritzer,G and Smart,B (eds) Handbook of Social Theory Sage Publications: London

Zwick,M (2001) ‘Understanding Imperfection’ In Ragsdell,G and Wilby,J (eds) (2001) Understanding Complexity Kluwer Academic/Plenum Publishers: New York 